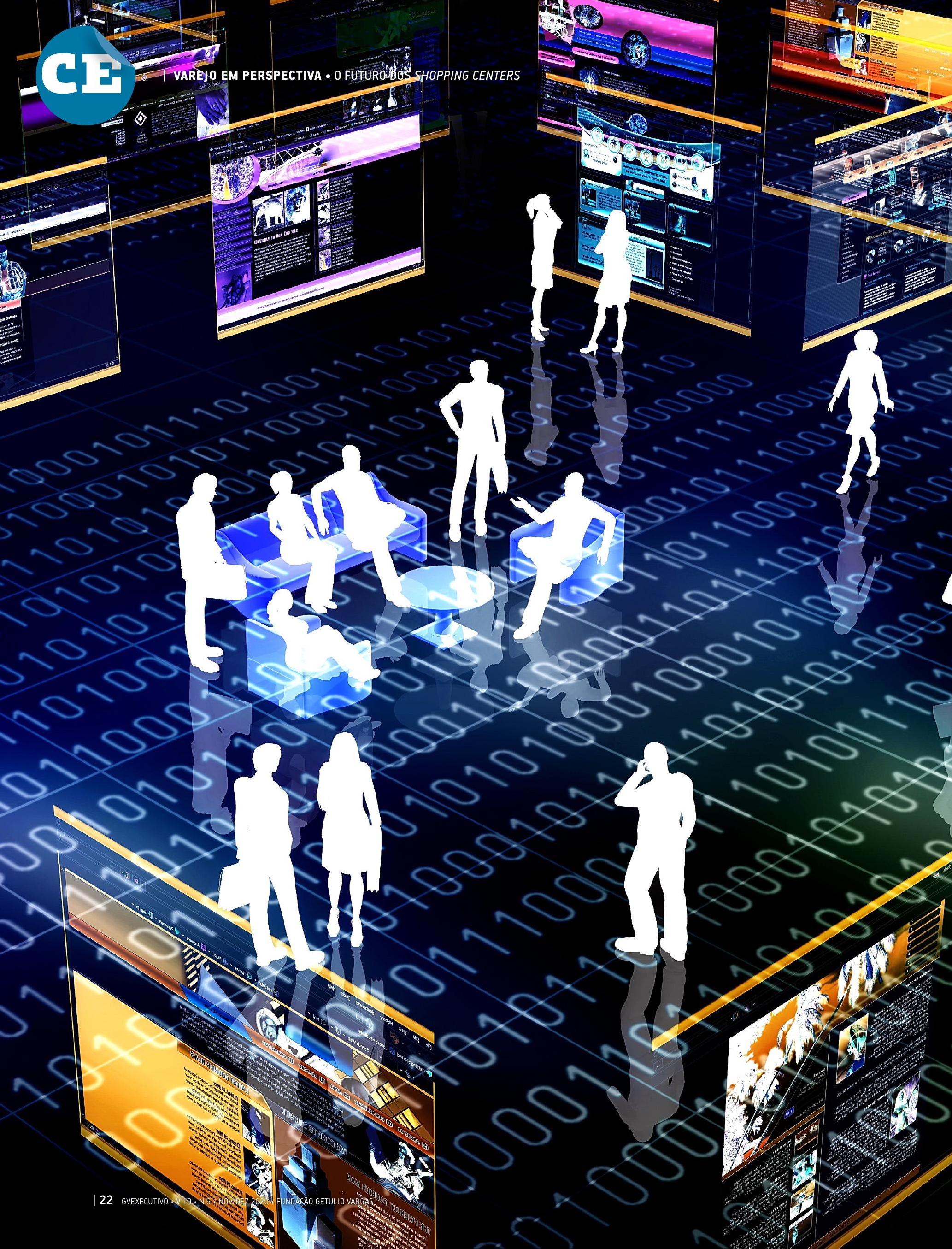




\section{O FUTURO DOS SHOPPING CENTERS}

| POR ALEXANDRE COELHO FERREIRA E GILBERTO SARFATI

\section{Os chamados templos de consumo serão bem diferentes de como se apresentam hoje no Brasil. Traçamos quatro cenários possiveis para 2040, que vão depender de como o consumidor vai se comportar e comprar física e virtualmente.}

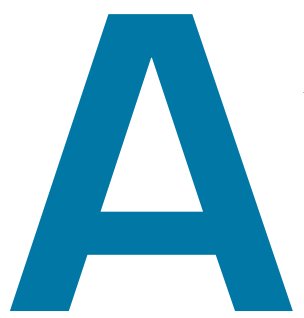

Covid-19 deixou, por meses, os shopping centers vazios. Mesmo na segunda metade de outubro, $40 \%$ dos consumidores brasileiros não tinham ainda voltado a colocar os pés nesses estabelecimentos, de acordo com levantamento da Associação Brasileira de Shopping Centers (Abrasce) em parceria com a Fronte Pesquisa e Análise de Mercado. A insegurança por causa da pandemia foi a principal razão, mas outros motivos também despontaram, como a preferência por compras online ou na rua, citada por um quarto dos entrevistados. A crise atual acentua mudanças tecnológicas e comportamentais do consumidor brasileiro que já colocavam um ponto de interrogação no futuro desses centros de compras.

Não seria a hora de repensar o modelo? Para projetar futuros cenários possíveis para os shopping centers, realizamos uma pesquisa científica em que foram consultados 51 especialistas, entre empreendedores da área, gestores de shoppings, lojistas, gerentes de loja e arquitetos e desenvolvedores de shoppings. Com base em duas grandes forças motrizes, canal de venda, comportamento do consumidor e sua migração ou não para o virtual, desenvolvemos quatro cenários para 2040 (veja na ilustração da página seguinte).

\section{AVATAR MALL: CANAL DE VENDA VIRTUAL + COMPORTAMENTO DO CONSUMIDOR VIRTUAL}

Os consumidores realizarão todas as compras pela internet. No caso de produtos de consumo diário, quando acabar o estoque em casa, automaticamente uma ordem de compra será enviada ao smartphone por diferentes dispositivos conectados à internet das coisas. Por um comando de voz no voice-commerce, será possível decidir sobre a reposição ou não dos produtos. Em plataformas de living commerce, espécie de shop tour de lojas nos smartphones, os consumidores poderão ter contato com vendedores para verificar produtos específicos e tirar dúvidas a respeito deles. Aplicativos avisarão quando algo novo que possa interessar chegar ao mercado.

O shopping como ambiente físico desaparecerá. Em seu lugar, haverá o shopping virtual no second life, um ambiente de realidade virtual que permite aos usuários se transportarem por avatares para o ambiente online, com o uso de óculos de realidade virtual. Com um clique, será possível se transportar para qualquer shopping do mundo e, então, andar por corredores, conversar com amigos, entrar nas lojas, assistir a espetáculos, fazer compras e, ao final da jornada, se desconectar. 


\section{OS QUATRO CENÁRIOS}

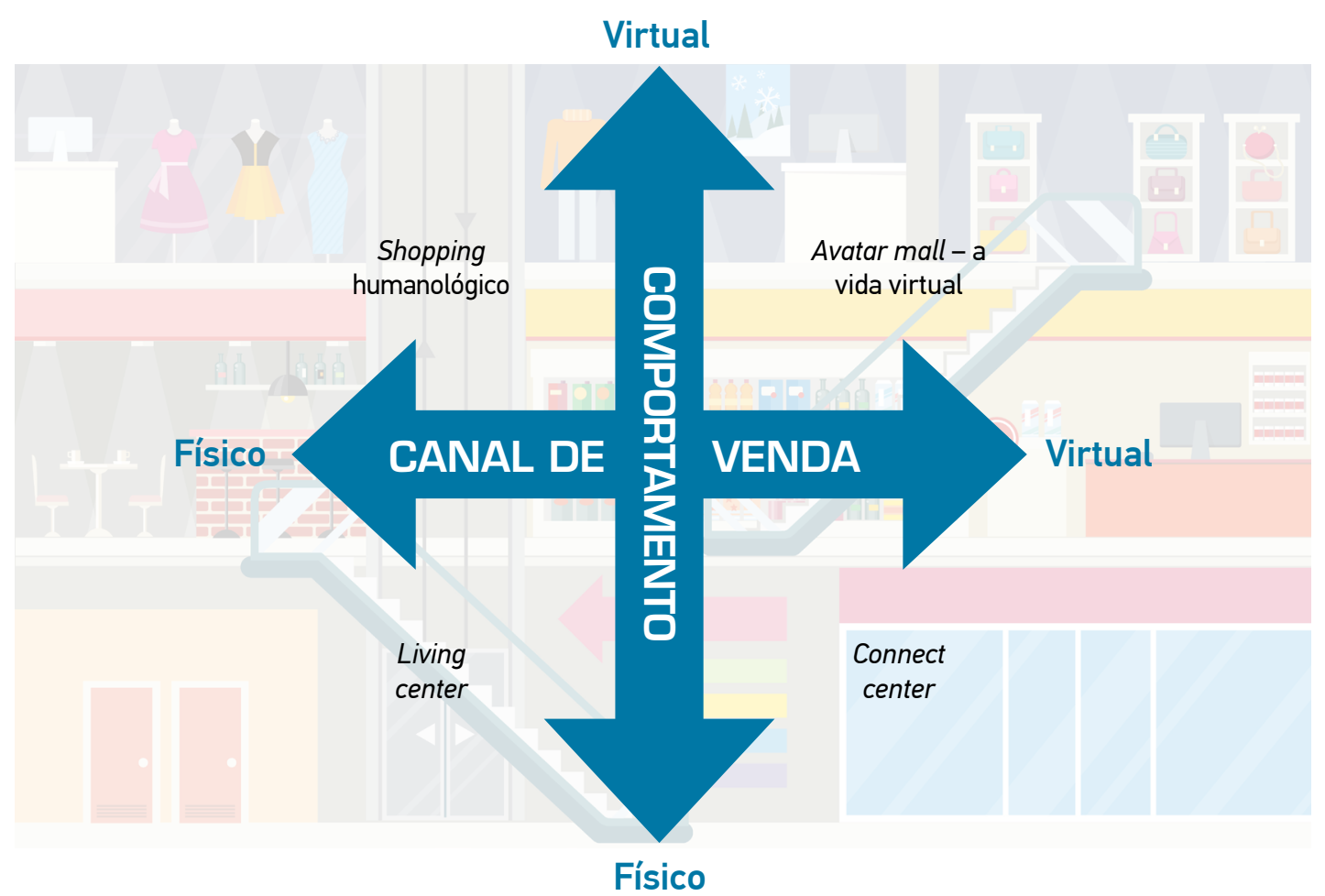

No shopping virtual, as experiências serão integralmente substituídas por tecnologias, em um ambiente divertido, conveniente e flexível. Painéis de bate-papo surgirão na tela durante o passeio. Conforme o consumidor passar na frente das lojas, elas enviarão mensagens com promoções personalizadas que possam interessá-lo.

\section{SHOPPING HUMANOLÓGICO: CANAL DE VENDA FÍSICO + COMPORTAMENTO DO CONSUMIDOR VIRTUAL}

Os consumidores vão ao shopping em busca de experiências, convivência e interação. Logo, os ambientes terão espaços mistos (fechados e abertos), flexíveis e de compartilhamento. O mix de lojas incluirá mais serviços pessoais, além das tradicionais lojas de conserto, por exemplo, englobando saúde e educação.

Com ferramentas sofisticadas de mineração e análise de dados, os shoppings poderão gerar informações capazes de customizar a jornada de compra. Assim, vão deixar de fazer sorteios e realizar campanhas promocionais que falam com todo mundo para fornecer ofertas personalizadas. Também terão plataformas ou aplicativos para fornecer informações de maneira objetiva e agradável.
Não haverá atritos entre o ambiente virtual e o físico, uma vez que a barreira entre essas duas dimensões deixará de existir. Como os consumidores chegarão ao shopping já muito bem informados pela etapa virtual, os vendedores deverão estar muito bem preparados para oferecer detalhes sobre os produtos. Além disso, os vendedores precisarão estar preparados para transmitir valores e propósitos da empresa.

\section{CONNECT CENTER: CANAL DE VENDA VIRTUAL + COMPORTAMENTO DO CONSUMIDOR FÍSICO}

O conceito multiuso dos outros modelos também estará presente no connect center. Lojas âncora não existirão mais, dando lugar a espaços de uso coletivo, que vão abrigar várias marcas diferentes. Haverá ainda espaços de descanso, similares aos de parques de rua. Os locais compartilhados poderão ter pistas de skate, palco de música e/ou ambiente para trabalho e estudo.

Os shoppings terão áreas verdes, estações para retirar os itens comprados na internet e um conceito que atenda a diferentes gerações, com arquitetura que facilite a locomoção dos mais velhos e escolhas alinhadas com os valores 
dos mais jovens, incluindo atenção na seleção de lojistas com preocupação socioambiental. Também vão desenvolver aplicativos para informar sobre promoções e produtos que os consumidores não conhecem, mas que, por seu perfil, teriam interesse em examinar mais de perto.

A aquisição de produtos ocorrerá no ambiente virtual, e os consumidores vão às lojas para, além de retirar e devolver itens, conhecer, examinar e testar os produtos que desejam adquirir - prática conhecida como showrooming. Com essa experiência e o atendimento customizado, os consumidores ficarão mais seguros de suas escolhas. Assim, os pontos de venda vão se transformar em minicentros de distribuição e hubs de experiência das marcas.

\section{LIVING CENTER: CANAL DE VENDA FÍSICO + COMPORTAMENTO DO CONSUMIDOR FÍSICO}

Mesmo em um mundo superconectado, a experiência e as relações humanas continuarão a ter grande importância para as pessoas, que buscarão shoppings onde possam resolver tudo. O shopping evoluirá de centro de compras para um local multiuso, que potencialmente atenderá a todas as necessidades das pessoas: morar, trabalhar, estudar, divertir-se, exercitar-se e consumir.

As compras de produtos altamente padronizados serão feitas no e-commerce. Lojas âncora e segmentos massificados vão dar lugar a negócios que entregam mais experiência, maior convívio e partilha, como alimentação e entretenimento. O mix das lojas físicas vai sofrer alterações profundas para atender a seis gerações diferentes de clientes e para ofertar mais serviços e conveniência.

No lugar de vendedores, haverá os style sellers, que, com base em uma gama enorme de informações dos consumidores, vão prestar consultoria. Quando o cliente concluir a compra, o serviço de delivery do shopping vai imediatamente entregar a mercadoria em sua casa.

\section{CARACTERÍSTICAS COMUNS}

Após a construção desses cenários, identificamos algumas características comuns que devem caracterizar o shopping do futuro:

- experiências significativas;

- forte oferta de serviços;

- interação do ambiente digital com o físico sem atrito;

- atendimento como diferencial.

Independentemente do cenário, os shoppings precisarão criar experiências para gerar sentido de comunidade aos frequentadores. As pessoas buscarão lugares que não sejam

\section{Independentemente do cenário, os shoppings precisarão criar experiências para gerar sentido de comunidade aos frequentadores, a fim de construírem uma conexão emocional forte.}

monótonos, com interação, entretenimento, cultura e sustentabilidade ambiental e social, a fim de construírem uma conexão emocional forte.

Os serviços precisarão atingir outro patamar de variedade e qualidade. Essa mudança influenciará desde o planejamento arquitetônico, que deverá ser capaz de atender às necessidades do perfil do consumidor local, reforçando a vocação de conveniência dos empreendimentos, até a relação interpessoal entre os clientes, vendedores e colaboradores do shopping.

Com o fim da barreira entre o ambiente físico e o digital, os dados gerados na jornada do cliente precisarão ser transformados em estratégias para sustentar o negócio. A experiência deverá ser personalizada e a combinação online e offline ser fluida e sem atrito. Os shoppings não conseguirão competir com a natureza ativa da internet. Dessa forma, será necessário incorporar o meio digital para proporcionar experiências de consumo significativas.

Para finalizar, a última característica comum a todos os cenários apresentados é o atendimento. Os espaços físicos serão criativos, inovadores, inteligentes e dinâmicos, proporcionando maior interação entre os consumidores e as marcas, porém o atendimento continuará a ser um diferencial relevante para aproximação dos clientes e relacionamento com eles. Terá o papel de encantar, exibindo conteúdo atraente e fortalecendo vínculos com as pessoas.

Independentemente do cenário, os shopping centers e seus lojistas devem se preparar para profundas mudanças, pois, mesmo no cenário em que os consumidores continuam a interagir e comprar no espaço físico, nada será como antes.

\footnotetext{
PARA SABER MAIS:

Alexandre Coelho Ferreira. Cenários prospectivos para shopping center no Brasil em 2040, 2020. Disponivel em: http://bibliotecadigital.fgv.br/dspace/handle/10438/29047

ALEXANDRE COELHO FERREIRA > Mestre pelo Mestrado Profissional em Gestão para a Competitividade (MPGC) da FGV EAESP > acferreira78@gmail.com GILBERTO SARFATI > Professor da FGV EAESP > gilberto.sarfati@fgv.br
} 